\title{
Reference Work at Amherst College Library
}

Mr. Pritchard is reference librarian, $\mathrm{Am}$ herst College Library.

$\mathrm{T}$ HE MAIN feature of reference work in the Amherst College Library is the close and continuing collaboration between the reference librarian and students writing papers and honors theses. This involves a relationship between student and librarian which ends only when the student has found all the material he needs. It begins when the student registers with the reference librarian as soon as he undertakes any research. The student describes his project and the librarian gets a clear idea of what he is attempting. He then asks what the student has done so far and in this way gains an insight into his preparation to do research. The librarian can then begin at the student's level to show him the next steps. It may be necessary to introduce him to the card catalog and the Readers' Guide to Periodical Literature, or he may be ready to hear about the special bibliographies in learned journals of the field in which he is working.

The first step in the collaboration between reference librarian and student has been taken, but this is only a beginning. During the conference the librarian makes a record of the student's name and topic and explains how he will work with him in gathering material. The student is instructed to report to the librarian whenever he sees his name posted on the reference call board, because this will mean the librarian has something to communicate.
Further assistance takes two forms: introducing the student to more and more specialized research tools and finding specific material for him either at his request or on the librarian's own initiative. It is not feasible from any point of view to tell a student all at once all the sources he should consult. The student would be confused and discouraged and the librarian would be under a strain to present everything pertinent. When, however, the student and librarian work together for a week or a month or more, the librarian as well as the student lives with the topic. During this time he is able to explore the resources of the library as thoroughly as the student's project demands and to watch for material in the ordinary round of his duties. While scanning book reviews, skimming new books, keeping an eye on incoming serials, even while answering a particular reference question ; the librarian discovers leads to a number of topics for which he is on the alert.

Informing a student of a new source of information can be done easily and sometimes instructively. The librarian makes a note which he clips to the front of the student's record card. At the same time he posts his name on the call board and lets the student consult him when it is convenient. Experience has shown that it is better to ask the student to copy the note rather than give it to him. It is good practice then to clip the note to the back of the student's card. In this way the librarian keeps a record of the assistance he has given a student and he can also show it to him 
again if the student loses his copy.

The librarian does not spoon-feed students. For example, if he finds a likely title in the card catalog under a subject heading not yet explored by the student, he will refer him to the subject heading rather than to the book itself. Or he will simply recommend a certain bibliography even though he has already gone through it and found several pertinent titles. At their next conference he may ask the student how productive this subject heading or that bibliography has proved to be.

In almost every instance the librarian has to decide whether to present the student with a general lead in the direction of a reference, a specific title complete with the call number, or even a text itself. The library competence of the student and the nature of the reference determine what the librarian will do. If he has encountered a pamphlet or a government document purely by chance, it is usually best to refer it to the student as specifically as possible at the same time pointing out where similar reference might be found.

A number of departments of the college, principally in the social sciences, have asked the reference librarian to address their honors students before they begin work on their theses. Here the reference librarian has the opportunity to call attention to items generally useful in their subject field and also to invite the students to confer with him individually. Reports of the reference program have spread among students and faculty with the result that students consult the reference librarian on their own initiative and more and more faculty members are asking the reference librarian to address their students.

The effects of this collaboration between student and librarian can be found in several areas of the library. More United States government documents have been used and a few students have learned to ask for them by serial document volume number. Bibliographic aids of all kinds have been given greater use. Finally the number of students who received continuing reference assistance almost doubled between the first and this second year of this program's operation. The library is an integral part of instruction.

\section{American International College Library Building}

\section{(Continued from page 148)}

regulate the windows in the main and lower level reading rooms and in the lower level stack area.

Another thing that bothers is the type of cinder block which we used. They are very porous and we discovered that sound carries through them. In many instances this is not important, but in some cases we found it necessary to insulate and plaster some walls which we had not intended to do. 'There are other quality cinder blocks available, but again, in order to economize we were forced to use a cheap grade.
Looking at the library as objectively as possible for one who is using it every day, we do feel that the good points outweigh enormously the things that irritate.

We like the good lighting, our adequate elevator, the feeling of space, the relation of one work area to another, the pleasing color, the lack of waste space in corridors and stairwells, and the attractive furnishings and equipment. As one student remarked a short time ago, "I just love to come in here and sit even when I don't have to study. It's great to think it is ours." 